\title{
СЕМАНТИЧЕСКИЙ СУБЪЕКТ И ИМПЛИЦИТНОСТЬ
}

\section{IMPLICIT SEMANTIC SUBJECT}

\section{A. Chervony}

Summary: The paper presents the investigation into implicit ways of expressing semantic subject. The author studied the reasons causing formal reduction of the subject. Implicitness of the semantic subject can be explained by the necessity to single out most meaningful element of a phrase in the communicative situation. Syntactic models with implicit semantic subjects make up a paradigm, the layers of which are bound by synonymous relations. The way of compensation allowing to determine the semantic subject are the context and the involvement into the communicative situation.

Keywords: subject, implicitness, semantics, syntactic model, paradigm, context, communicative situation.
K ак определяет словарь лингвистических терминов имплицитный (франц. implicite - подразумеваемый, скрыто содержащийся, от лат. implicitum). Невыраженный, подразумеваемый; неразвернутый [1, с. 88].

В лингвистике под имплицитностью - свойством быть «невыраженным», «скрытным» понимают то содержание высказывания, которое лексически не представлено в высказывании, а логически выводится путем умозаключений, которые строятся на информированности, на основе знаний говорящего. Знания как наиболее значимая часть информации включают в себя прецедентные тексты, позволяющие извлекать смысл высказывания в соответствии с ситуацией, смысл высказывания раскрывается также в результате предугадывания языковым сознанием ожидаемого в контексте событий высказывания.

Семантический субъект, под которым понимается реальный деятель, может быть как определенным, конкретизированным, однозначно понимаемым коммуникантами и адекватным образом - лексически выраженным в предложении, так и неопределенным, семантически затушеванным и даже формально не представленным при описании событий, в которых он играет ведущую роль, роль протагониста.
Червоный Александр Михайлович

Д.филол.н., дочент, Таганрогский институт имени А.П. Чехова (филиал) ФГБОУ ВПО «РГЭУ (РИНХ)» ckutrik@yandex.ru

Аннотация: Статья посвящена рассмотрению имплицитности выражения семантического субъекта. В работе рассмотрены причины, вызывающие формальную редукцию субъекта. Имплицитность семантического субъекта объясняется необходимостью выделить языковыми средствами наиболее значимый для говорящего элемент коммуникативной ситуации. Синтаксические модели с имплицитным субъектом составляют парадигму, которой связаны синонимичными отношениями. Компенсаторными возможностями, позволяющими детерминировать семантический субъект, являются контекст и вовлеченность в коммуникативную ситуацию.

Ключевые слова: субъект, имплицитность, семантика, синтакическая модель, парадигма, контекст, коммуникативная ситуация

Смысл всего предложения и в том числе детерминация семантического субъекта осуществляется в процессе речевого акта, в результате чего предложение как единица системы языка трансформируется в высказывание.

Семантический субъект может стать имплицитным в результате его формального устранения из структуры предложения. Вследствие редукции субъекта синтаксическая конструкция приобретает более сжатую, конденсированную форму выражения по отношению к предложению с симметричным выражением планов формы и содержания.

Устранение реального деятеля имеет место в конструкциях, не реализующих валентность глагола в полной мере [2]. К таким синтаксическим конструкциям следует отнести разные типы пассивных конструкций, конструкции с глаголами - конверсивами (получать, принимать и т.д.). Субъект выведен так же из состава синтаксической конструкции, в которых представлен метонимически, он выражается косвенно, лексическими единицами, обозначающими средства передвижения, разной степени сложности механизмами, орудиями труда, оружием, техникой, приборами и т.д. (Машина остановилась на углу. Орудия перестали стрелять). Субъект имплицитен при выражении антропоморфного процес-

\footnotetext{
Исследование выполнено при финансовой поддержке Российского фонда фундаментальных исследований (РФФИ) в рамках научного проекта № 19-012-00062 «Полифония семантического субъекта (на материале русского, французского, английского и немецкого языков)», проводимого в ФГБОУ ВО «РГЭУ (РИНХ)»; руководитель - доктор филол. наук, доцент, заведующий кафедрой немецкого и французского языков А.М. Червоный
} 
са номинализацией. (Раздался выстрел. Послышался крик.)

Вследствие имплицитности субъекта наиболее значимым в информационном и коммуникативном плане становится выражение того или иного элемента действительности, в центре внимания может оказаться объект воздействия, результат действий субъекта и т.д.[4, с. 122]. Рече-мыслительный механизм позволяет описывать ситуацию, разделяя действительность на фрагменты. От коммуникативной интенции говорящего зависит выбор той или иной синтаксической конструкции, а также выбор лексических единиц и их занимаемая позиция в порядке слов в предложении. Синтаксические конструкции, в которых семантический субъект имплицитен, не способны дать полного описания происходящих событий. Однако ментально, субъект достраивает имплицитные элементы, он с разной степенью определенности отмечает связи, отношения, в том числе связь (и) формально невыраженного семантического субъекта с зависимыми от него элементами ситуации, представленными в конструкции лексическими единицами, отражающими логико-семантические отношения «субъект (инструмент) - действие (состояние) - объект». Возможность речевой вариативности позволяет представить ту или иную ситуацию разными лингвистическими способами, с разных позиций, фокусируя внимание на важном для говорящего элементе с целью его полнооформленного выражения с учетом логикокоммуникативной направленности сообщения, структурно отраженной в синтаксическом порядке слов в предложении.

Следует отметить: вне зависимости от имплицитности/эксплицитности семантического субъекта неизменным, общим - интенсионалом остается смысл, содержащихся в конструкциях, семантика которых предполагает обязательное наличие реального деятеля.

Реальный деятель выявляется таким образом не в рамках отдельно взятой синтаксической модели предложения, а вне ее, на основании более широкого контекста, ситуации или универсальных знаний об окружающей действительности.

Возможен и обратный процесс, процесс реконструкции контекста, который может быть восстановлен по отдельной синтаксической модели. Реконструкция контекста, т.е. выхода за пределы отдельного предложения, позволяет установить реального деятеля - семантический субъект.

Предложения с формально разным выражением семантического субъекта - от имен собственных и местоимений «я» до полной формальной имплицитно- сти - составляют парадигму синтаксических моделей, имеющих общий интенсионал «действие (состояние) человека». Парадигма моделей имеет общую прототипическую синтаксическую модель, в конструкции которой симметрично представлены лексические, семантические и синтаксические компоненты: Петр (человек) строит дом. Семантический субъект - реальный деятель Петр - имя сущ., одуш. конкр., 3 л., ед.ч., употреблено в им.n., занимает в предложении позицию подлежашего, субъект совершает действие - cmpoum - выражено глаголом в 3-ем л. ед. ч., наст. вр., действ. залога, объектом действия, вернее его результатом является дом - имя сущ. неодуш.. 3 л. ед.ч., вин. п. выполняет синтаксическую функцию прямого дополнения. Однако, как показал анализ фактического материала, данное соответствие - симметрия формы и содержание в предложении довольно часто нарушается. Неопределенность, неконкретность выражения субъекта, его семантическая «затушеванность», его частичное обозначение и полное устранение из синтаксического состава предложения приводят к асимметрии обозначаемого и обозначающего.

Вариативность, динамизм языка/речи проявляется в наличии и функционировании значительного числа форм выражения одного и того же значения (понятия). В этом проявляется богатство языка, его мощь.

Таким образом, формам выражения семантического субъекта, а также синтаксическим моделям - вариантам пропопозиции, прототипической эталонной модели присуща переменная функция, в то время как семантическое значение остается неизменным и является константой.

Ввиду вышесказанного, между моделями, обладающими, по сути, одним семантическим значением, возникают отношения синонимичности, синтаксические модели в зависимости от конкретных речевых ситуаций способны взаимозамещаться без ущерба для транслируемой информации. Выбор формы выражения субъекта и той или иной синтаксической конструкции остается за говорящим, который учитывает все языковые и внеязыковые факторы.

Парадигма форм выражения реального деятеля нашла подтверждение в концепции упаковки (packaging) у. Чейфа.

В синтаксических моделях наблюдается асимметрия, содержащегося в предложении сообщаемого (message) и того, в какой упаковке оно представлено. Упаковка, по У. Чейфу, - это оформление предложения, которое характеризуется способом подачи предложения говорящим [3, с. 277-278]. 
Имплицитность семантического субъекта объясняется намерением говорящего сконцентрироваться на одном из компонентов ситуации, в которой протогонистом выступает семантический субъект.

Несмотря на формальное отсутствие субъекта в структуре предложения на уровне семантики выявля- ются антропоморфные характеристики выражаемого действия или состояния.

Контекст и вовлеченность индивидов в коммуникативную ситуацию позволяют компенсировать формально нулевую форму выражения семантического субъекта, в той или иной степени детерминировав его наличие.

\section{ЛИТЕРАТУРА}

1. Розенталь Д. Э., Теленкова М. А. Словарь-справочник лингвистических терминов. Изд. 2-е. - М.: Просвещение, 1976. - 399 с.

2. Теньер Л. Основы структурного синтаксиса. - М.: Прогресс, 1988. - 654 с.

3. Чейф У. Данное, контрастивность, определенность, подлежащее, топики и точка зрения. //Новое в заруб, лингвистике. Вып. 11. М.: Прогресс, 1982. - 463 с.

4. Червоный А.М. Реконструкция процесса устранения и трансформации семантического субъекта в дискурсе (на материале французского языка) // Вестник Пятигорского государственного лингвистического университета, 2012. -№ 2. - С. 118-122.

(с) Червоный Александр Михайлович (ckutrik@yandex.ru).

Журнал «Современная наука: актуальные проблемы теории и практики»

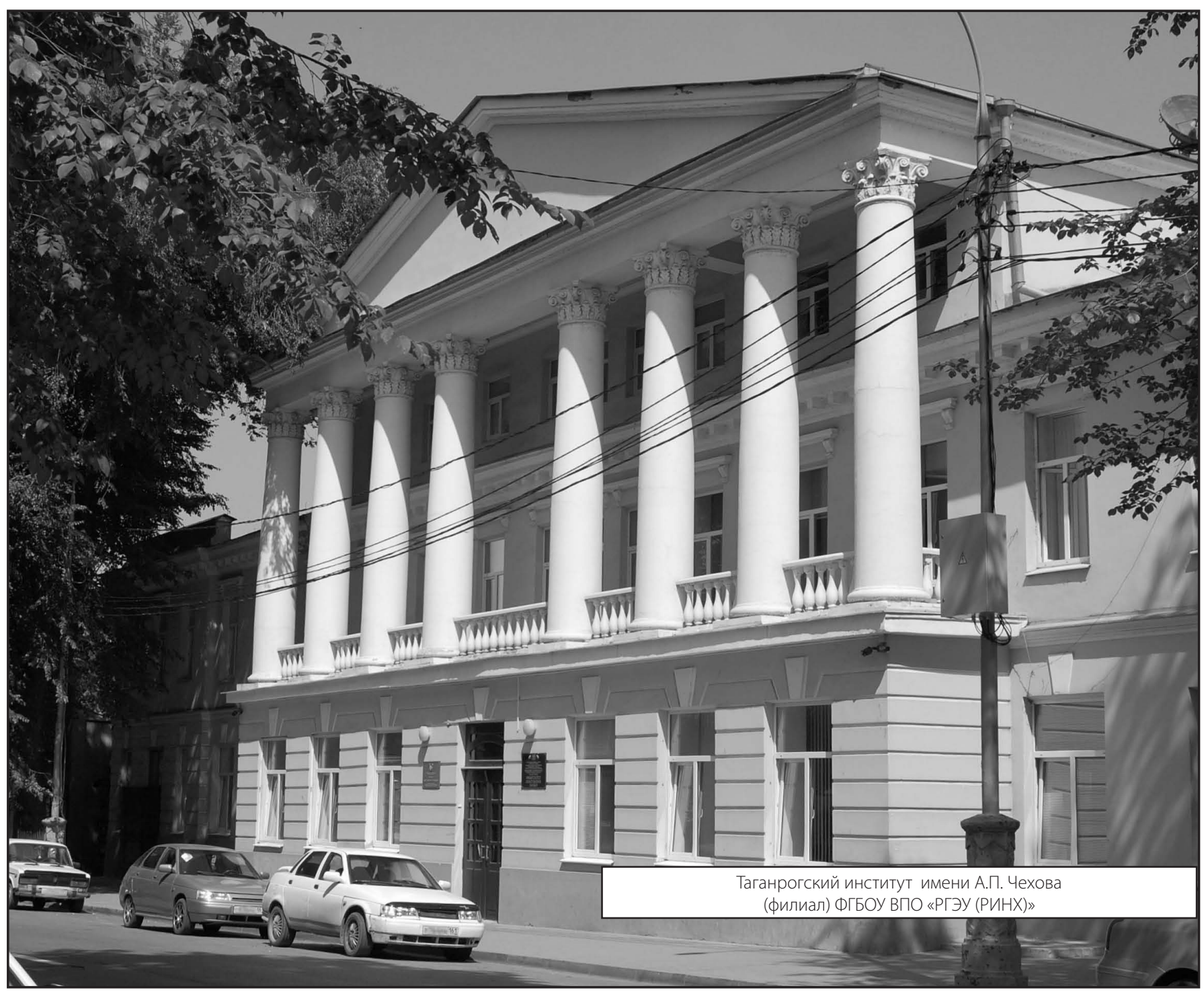

